\title{
Investigation of Cervical Tumor
} Biopsies for Chromosomal Loss of Heterozygosity (LOH) and Microsatellite Instability (MSI) at the HLA II Locus in HIV-1/HPV Co-infected Women

\section{OPEN ACCESS}

Edited by:

Giuseppe Vizzielli,

Agostino Gemelli University

Polyclinic, Italy

Reviewed by:

Emanuele Perrone,

Department of Women's and

Children's Health, A. Gemell

University Hospital Foundation, Italy

Martina Borghese,

Hospital Mauritian Turin, Italy

Martina Arcieri,

University of Eastern Piedmont, Italy

${ }^{*}$ Correspondence:

Ramadhani Chambuso

rchambuso@outlook.com

Specialty section:

This article was submitted to

Women's Cancer,

a section of the journal

Frontiers in Oncology

Received: 25 July 2019 Accepted: 09 September 2019

Published: 15 October 2019

Citation:

Chambuso R, Kaambo E, Denny L,

Gray CM, Williamson A-L,

Migdalska-Sęk M, Agenbag G,

Rebello G and Ramesar R (2019)

Investigation of Cervical Tumor

Biopsies for Chromosomal Loss of

Heterozygosity $(\mathrm{LOH})$ and Microsatellite Instability (MSI) at the

HLA II Locus in HIV-1/HPV

Co-infected Women.

Front. Oncol. 9:951.

doi: 10.3389/fonc.2019.00951
Ramadhani Chambuso ${ }^{1,2 *}$, Evelyn Kaambo ${ }^{3,4}$, Lynette Denny ${ }^{5,6}$, Clive M. Gray ${ }^{7,8}$, Anna-Lise Williamson ${ }^{3,5,7}$, Monika Migdalska-Sęk ${ }^{9}$, Gloudi Agenbag ${ }^{1,7}$, George Rebello ${ }^{1}$ and Raj Ramesar ${ }^{1,7}$

${ }^{1}$ MRC Unit for Genomic and Precision Medicine, Division of Human Genetics, Department of Pathology, Faculty of Health Sciences, University of Cape Town, Cape Town, South Africa, ${ }^{2}$ Department of Gynaecology, Morogoro Regional Referral Hospital, Morogoro, Tanzania, ${ }^{3}$ Division of Medical Virology, Department of Pathology, Faculty of Health Sciences, University of Cape Town, Cape Town, South Africa, ${ }^{4}$ Department of Biochemistry and Medical Microbiology, University of Namibia School of Medicine, Windhoek, Namibia, ${ }^{5}$ South African Medical Research Council, Clinical Gynaecological Cancer Research Centre, University of Cape Town, Cape Town, South Africa, ${ }^{6}$ Department of Obstetrics and Gynaecology, Groote Schuur Hospital, University of Cape Town, Cape Town, South Africa, ${ }^{7}$ Institute of Infectious Disease and Molecular Medicine, University of Cape Town, Cape Town, South Africa, ${ }^{8}$ Division of Immunology, Department of Pathology and National Health Laboratory Service, University of Cape Town and Groote Schuur Hospital, Cape Town, South Africa, ${ }^{9}$ Department of Biomedicine and Genetics, Medical University of Lodz, Lodz, Poland

Background: A subgroup of women who are co-infected with human immunodeficiency virus type 1 (HIV-1) and human papillomavirus (HPV) progress rapidly to cervical disease regardless of high CD4 counts. Chromosomal loss of heterozygosity $(\mathrm{LOH})$ and microsatellite instability (MSI) are early frequent genetic alterations occurring in solid tumors. Loss of an allele or part of a chromosome can have multiple functional effects on immune response genes, oncogenes, DNA damage-repair genes, and tumor-suppressor genes. To characterize the genetic alterations that may influence rapid tumor progression in some HIV-1-positive women, the extent of LOH and MSI at the HLA II locus on chromosome $6 p$ in cervical tumor biopsy DNA samples with regard to HIV-1/HPV co-infection in South African women was investigated.

Methods: A total of 164 women with cervical disease were recruited for this study, of which 74 were HIV-1-positive and 90 were HIV-1-seronegative. DNA from cervical tumors and matched buccal swabs were used for analyses. Six fluorescently-labeled oligonucleotide primer pairs in a multiplex PCR amplification were used to study LOH and MSI. Pearson chi-squared test for homogeneity of proportions using an exact $p$ value, a two-proportion Z-score test, ROC curves and a logistic regression model were used for statistical analyses. All $p$-values were corrected for false discovery rate (FDR) using the Benjamini-Hochberg test and the adjusted $p$-values ( $q$-values) were reported. All tests were significant when both $\mathrm{p}$ and $q<0.05$. 
Results: Tumor DNA from HIV-1/HPV co-infected women demonstrated a higher frequency of $\mathrm{LOH} / \mathrm{MSI}$ at the HLA II locus on chromosome 6p21.21 than tumor DNA from HIV-1-seronegative women (D6S2447, 74.2 vs. 42.6\%; $p=0.001, q=0.003$ ), D6S2881 at 6p21.31 (78.3 vs. 42.9\%; $p=0.002, q=0.004)$, D6S2666 at $6 \mathrm{p} 21.32$ (79 vs. $57.1 \% ; p=0.035, q=0.052$ ), and D6S2746, at $6 p 21.33$ (64.3 vs. $29.4 \% ; p<0.001$ $q<0.001)$, respectively.

Conclusions: HPV infection alone can induce LOH/MSI at the HLA ॥l locus in cervical tumor DNA, whereas HIV-1 co-infection exacerbates it, suggesting that this may accelerate cervical disease progression in a subgroup of HIV-1-positive women.

Keywords: cervical cancer, loss of heterozygosity, microsatellite instability, HLA II locus, HIV-1/HPV co-infection, host molecular genetics, genetic alterations

\section{INTRODUCTION}

Women who are co-infected with Human Immunodeficiency Virus type 1 (HIV-1) and Human papillomavirus (HPV) are at high risk of developing cervical precancerous lesions (1). These precancerous lesions in HIV-1/HPV co-infected women are more aggressive, but only a small subset progress rapidly to invasive cervical cancer (ICC). This progression is unrelated to CD4 counts or antiretroviral (ARV) therapy $(2,3)$. What is not clear, however, is how and why this rapid cervical carcinogenesis is only observed in some HIV-1/HPV co-infected women (4).

Both HIV-1 and high-risk HPV (Hr-HPV) are classified as carcinogenic viruses (5). On the one hand, extrachromosomal HPV viral genomes often integrate into the host genome. This integration into the host genome drives the oncogenic process due to the overexpression of HPV viral oncoproteins E6 and E7 (6), which in turn, lead to inactivation of critical host DNA-damage-repair checkpoints during the cell cycle (7). Inactivation of the cell cycle checkpoints results in the accumulation of uncorrected mutations during normal DNA replication. These mutations increase host genomic instability and lead to further genetic alterations $(8,9)$. On the other hand, intracellular HIV-1 Tat proteins can interact directly with the $R b$ and $P 53$ tumor-suppressor genes in the host (10, 11). This interaction induces increased cell proliferation, which promotes the effects of HPV oncoproteins E6 and E7 in cervical carcinogenesis (12).

In two previous studies, we reported that, host molecular genetic variations at the Human Leucocyte Antigen class II (HLA II) locus on chromosome $6 \mathrm{p}$ and accumulation of repeated genetic alterations, can influence the rate of cervical disease progression in HIV-1/HPV co-infected women $(4,13)$. Furthermore, Harima et al. (14), reported that chromosome 6p was one of the chromosomal regions most frequently involved in the genetic alterations detected in cervical cancer. The availability of tumor biopsies in women with cervical disease can be used to interrogate the host genome for individualized tumor-specific early molecular oncogenic drivers (15). Loss of heterozygosity (LOH) and microsatellite instability (MSI) are among the most common earliest genetic alterations, and molecular oncogenic drivers, to occur in solid tumors including cervical cancer $(14,16)$. Both LOH and MSI may lead to the loss of microsatellite alleles, chromosomal loci, or single nucleotide polymorphisms (17).

MSI is a locus-specific change in the length of a short tandem repeat of nucleotide sequence in tumor genomic DNA when compared to the length in the normal genomic DNA (e.g., derived from white blood cells) from the same patient (18). MSI is caused by mutational inactivation of genes involved in DNA damage-repair (19). LOH at chromosomal level is the loss of one copy of an allele or a chromosomal locus in a certain region of a chromosome. If both copies of a gene are inactivated, $\mathrm{LOH}$ can result in inactivation of functional tumor-suppressor genes, oncogenes, immuneresponse genes, and DNA damage-repair genes that occur in the region of the chromosomal loss $(20,21)$. Inactivation of these important genes leads to physiologically uncontrolled cell growth and cell division in tissues where the LOH/MSI has occurred (22).

We previously hypothesized that HIV-1/HPV co-infection provokes additional genetic alterations at the HLA II locus to influence the rate of cervical disease progression in a subset of HIV-1-positive women (4). Furthermore, accumulation of repeated genetic alterations, can influence the rate of cervical disease progression in HIV-1/HPV co-infected women (4). In the early stages of the carcinogenic process, genetic alterations (LOH/MSI) can be identified in the tumor genomic DNA by using specific DNA markers (17). LOH/MSI can be studied in an individual's tumor genomic DNA, and compared to its status in a matched control genomic DNA from the same patient (17).

We investigated our hypothesis by using host genomic DNA fragments, analyzed in a multiplex polymerase chain reaction (PCR) using a capillary array electrophoresis platform. We used six fluorescently-labeled oligonucleotide primer pairs; BAT 26, D6S266, D6S2447, D6S1666, D6S2746, and D6S2881 to study chromosomal LOH/MSI in cervical tumor genomic DNA. These were compared to matched control DNA derived from buccal mucosa from the same patient, with regard to HIV-1/HPV co-infection in women histologically diagnosed with cervical disease in South Africa. 


\section{METHODS}

\section{Research Ethics}

All procedures were performed in accordance with guidelines of The Declaration of Helsinki. Ethical approval for the study was granted by the Human Research Ethics Committee of; the University of Cape Town (Number; HREC903/2015), all respective hospitals' Gynecology departments, the Department of Health of the Western Cape Government, and the South African National Health Laboratory Service. Consent forms were available in the language of the subject's choice and were signed in front of a witness. This was after detailed discussion with patients regarding the aims and nature of the study. A trained registered nurse who was fluent in the local languages explained the details of the study and answered all questions from the patients before their consent was requested.

\section{Study Design, Subjects, and Samples}

As part of a large ongoing hospital-based project, a total of 200 patients were recruited from three hospitals in the Western Cape, namely; the Groote Schuur Hospital, Somerset Hospital and Victoria Wynberg Hospital between June 2016 to March 2017. All patients were referred from peripheral health centers to these three hospitals after receiving abnormal Pap smear results after routine cervical screening. Patients were recruited from: the outpatient gynecological cancer assessment clinics, colposcopy clinics, and the gynecological emergency rooms. The only criterion for recruitment was that the patient be newly diagnosed with cervical disease. The age distribution, in years, ranged from 24 to 91, with the majority of women in the age group between 30 and 40 years. Of these 200 women, 164 were fully investigated in this study.

Prior to the collection of buccal swabs, patients rinsed their mouths with sterile water, and mechanically chewed both inner buccal mucosal walls for at least $30 \mathrm{~s}$. Both sides of buccal mucosa were scraped with a "DNA collector dry cotton swab stick" (Thermo Fisher Scientific, Johannesburg, South Africa) at least 20 times per side, as described according to the manufacturer's protocol. The buccal swabs were used to extract normal epithelial control DNA which were compared with abnormal tumor DNA from the same patients.

According to the South African HIV-1 testing algorithm, peripheral whole blood $(4 \mathrm{ml})$ was collected in EDTA tubes (BD Vacutainer $^{\circledR}$, Johannesburg, South Africa). Approximately $20 \mu \mathrm{l}$ of the collected peripheral whole blood was used for rapid HIV-1 antibody testing (Determine, Alere, Inc., Johannesburg, South Africa) (23).

Gynecologists used colposcopy inspection to collect punch biopsies of abnormal cervical lesions for histopathology analyses and HPV genotyping. All patients were recruited in this study before the initiation of the radiotherapy or chemotherapy treatment in order to avoid the consequences of DNA damage during cancer therapy (24).

\section{Tumor DNA Extraction and PCR Amplification}

Genomic DNA was extracted using Qiagen ${ }^{\circledR}$ QIAamp DNA Mini purification kit (Qiagen, Johannesburg, South
Africa) according to the manufacturer's protocol. The concentration of the extracted DNA was quantified by a Nanodrop ${ }^{\circledR}$ Spectrophotometer (Thermo Fisher Scientific, Johannesburg, South Africa). The DNA was diluted using nuclease free water (Thermo Fisher Scientific, Johannesburg, South Africa) to a recommended final concentration of $0.2 \mathrm{ng} / \mu \mathrm{l}$ of total DNA. The integrity of genomic DNA was tested by resolving DNA fragments on a $1 \%$ agarose gel by electrophoresis (Bio-Rad, Johannesburg, South Africa), migrated for $1 \mathrm{~h}$ at $100 \mathrm{~V}$ using $0.2 \mathrm{ng} / \mu \mathrm{l}$ of total DNA and $2 \mu \mathrm{L}$ of orange loading dye (Thermo Fisher Scientific, Johannesburg, South Africa), followed by staining with ethidium bromide (Sigma-Aldrich, Johannesburg, South Africa) and visualization on a UVtransilluminator and the image was captured using a gel documentation system (Bio-Rad, Johannesburg, South Africa) (25). Each DNA sample was graded, according to the electrophoretic migration of sample DNA compared with 100 bp weight ladder (Thermo Fisher Scientific, Johannesburg, South Africa).

The extracted DNA was amplified by PCR-based assays using six fluorescently-labeled forward primers with the pair names, dyes and sequence as described in Table 1 (All primers were diluted to $20 \mathrm{ng} / \mu \mathrm{l})$. The dream-Taq ${ }^{\circledR}$ PCR master-mix $12.5 \mu \mathrm{l}(1.5 \mathrm{mmol} \mathrm{MgCl} 2,200 \mathrm{mmol}$ dNTPs, 1 unit Taq DNA polymerase) (Thermo Fisher Scientific, Johannesburg, South Africa) was used for amplification according to the manufacturer's protocol. The PCR was carried out in $25 \mu \mathrm{l}$ total reaction volumes, each containing $2 \mu \mathrm{l}$ of template DNA, $1 \mu \mathrm{l}$ of each primer (Forward and reverse) and $8.5 \mu \mathrm{l}$ of nuclease free water (Thermo Fisher Scientific, Johannesburg, South Africa). The reaction mixture was heated to $95^{\circ} \mathrm{C}$ for $7 \mathrm{~min}$, followed by 35 cycles, each consisting of $30 \mathrm{~s}$ denaturation at $94^{\circ} \mathrm{C}, 30 \mathrm{~s}$ annealing at $53^{\circ} \mathrm{C}, 30 \mathrm{~s}$ extension at $72^{\circ} \mathrm{C}$, and a final 7 -min extension at $72^{\circ} \mathrm{C}$. The PCR amplification products $(5 \mu \mathrm{l})$ were subjected to electrophoresis (Bio-Rad, Johannesburg, South Africa) on $1 \%$ agarose gel in $1 \times$ Tris-acetate-EDTA buffer at $100 \mathrm{~V}$ for $1 \mathrm{~h}$ and stained with ethidium bromide (Sigma-Aldrich, Johannesburg, South Africa). The images were obtained in a gel documentation system (Bio-Rad, Johannesburg, South Africa) with the expected amplicon sizes for each marker as described in Table 1.

\section{HPV DNA Detection and Genotyping}

Tumor genomic DNA was diluted using nuclease free water (Thermo Fisher Scientific, Johannesburg, South Africa) to reach a recommended final concentration of $0.2 \mathrm{ng} / \mu \mathrm{l}$ of the total DNA. PCR-based Roche Linear Array ${ }^{\circledR}$ HPV genotyping test (Roche Molecular Systems, Pleasanton, CA, USA) which identifies 37 different HPV genotypes (HPV-6, -11, -16, $-18,-26,-31,-33,-35,-39,-40,-42,-45,-51,-52,-53$, $-54,-55,-56,-58,-59,-61,-62,-64,-66,-67,-68,-69$, $-70,-71,-72,-73,-81,-82,-83,-84,-89$ (HPV-CP6108) and -IS39) was used for typing HPV according to the manufacturer's instructions. All 37 different HPV genotypes were detected accordingly. 
TABLE 1 | Marker names, nucleotide sequences of primers, chromosomal positions, and the fluorescent dyes used for investigation of $L O H$ and MSI at the respective loci.

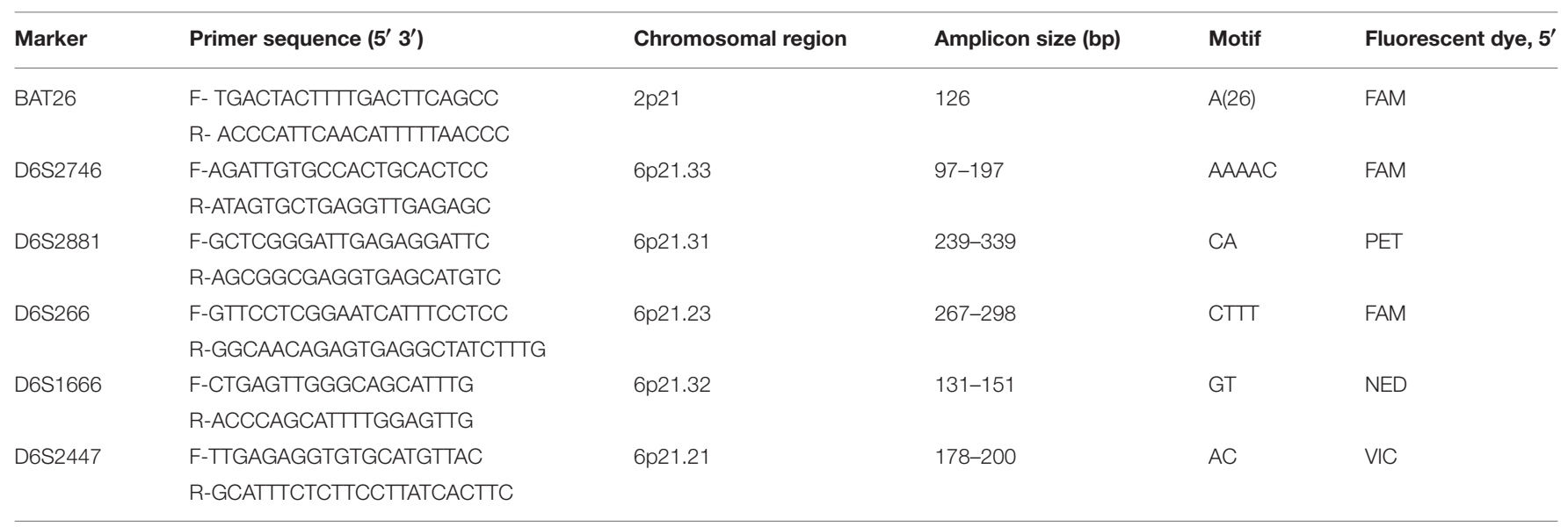

\section{Buccal Swab DNA Extraction and PCR Amplification}

In order to preserve the DNA, all buccal swabs were air dried for at least $20 \mathrm{~min}$ after collection and then frozen at $-20^{\circ} \mathrm{C}$, until processed. The genomic DNA was extracted using Qiagen QIAamp DNA extraction kit (Qiagen, Johannesburg, South Africa) according to manufacturer's protocol (26). Briefly, each swab was placed in a $2 \mathrm{ml}$ micro centrifuge tube and mixed with $20 \mu l$ proteinase $\mathrm{K}$ and $600 \mu \mathrm{l}$ Buffer ATL, supplied in the kit. The mixture was placed in a thermomixer and incubated at $56^{\circ} \mathrm{C}$ with shaking at $900 \mathrm{rpm}$ for at least $1 \mathrm{~h}$; where after further extraction procedures were followed as per the manufacturer's protocol. All samples were eluted according to the manufacturer's instructions. The integrity of genomic DNA was tested as described in the previous section.

The extracted DNA was amplified by PCR using human betaglobin gene primers - Bg1 F(5'-CAACTTCATCCACGTTCACC$\left.3^{\prime}\right)$ and $\mathrm{Bg} 2 \mathrm{R}\left(5^{\prime}\right.$-GAAGAGCCAAGGACAGGTAC-3'), and $12.5 \mu \mathrm{l}$ Dream-Taq PCR master-mix (1.5 mmol MgCl2, 200 mmol dNTPs, 1 unit Taq DNA polymerase) (Thermo Fisher Scientific, Johannesburg, South Africa) according to the manufacturer's protocol. The PCR was carried out in $25 \mu \mathrm{l}$ total reaction volumes, each containing $2 \mu \mathrm{l}$ of template DNA, $0.5 \mu \mathrm{l}$ of each primer, and $10.5 \mu \mathrm{l}$ of nuclease free water (Thermo Fisher Scientific, Johannesburg, South Africa). The reaction mixture was heated to $95^{\circ} \mathrm{C}$ for $7 \mathrm{~min}$, followed by 35 cycles, each consisting of $30 \mathrm{~s}$ denaturation at $94^{\circ} \mathrm{C}, 30 \mathrm{~s}$ annealing at $53^{\circ} \mathrm{C}, 30 \mathrm{~s}$ extension at $72^{\circ} \mathrm{C}$, and a final 7 -min extension at $72^{\circ} \mathrm{C}$. The PCR amplification products $(5 \mu \mathrm{l})$ were subjected to electrophoresis (Bio-Rad, South Africa) on 1\% agarose gel in $1 \times$ Tris-acetate-EDTA buffer at $100 \mathrm{~V}$ for $1 \mathrm{~h}$ and stained with ethidium bromide (Sigma-Aldrich, Johannesburg, South Africa). The images were obtained in a gel documentation system (Bio-Rad, Johannesburg, South Africa) with expected amplicon size of $268 \mathrm{bp}$.

\section{LOH/MSI Analysis}

LOH/MSI analysis was carried out in a "blinded" fashion, i.e., without knowledge of HIV-1 or HPV infection status. $\mathrm{LOH} / \mathrm{MSI}$ was assessed at six highly polymorphic repeat markers;
BAT26, D6S2447, D6S266, D6S2666, D6S2746, and D6S2881. The markers were chosen on the basis of their high heterozygosity informative content value of 0.7 in the HLA II gene and map position on chromosome $6 \mathrm{p}$ as described in the NCBI database (https://www.ncbi.nlm.nih.gov/) with supplementary mapping information, where necessary, provided in the Genome Reference Consortium (https://www.ncbi.nlm.nih.gov/grc) and the Human Genome Database (http://morissardjerome.free. fr/infobiogen/www.gdb.org/gdb/). The forward primers were labeled with fluorescent dyes: FAM, NED, PET, or VIC, as shown in Table $\mathbf{1}(27,28)$.

Five of the markers studied are located in the HLA II locus (Chromosome 6p21), and one marker, BAT26, was located in the vicinity of the $\mathrm{MSH} 2$ mismatch-repair gene on chromosome 2 p21. BAT 26 marker was used in order to compare it with other markers in the analyses due to its high percentage of $\mathrm{LOH}$ and its reported accuracy in predicting LOH/MSI as previously studied in colorectal tumors (29).

Multiplex PCR reactions were performed and the amplified PCR products were analyzed by capillary array electrophoresis and GeneMapper ${ }^{\circledR}$ software (Applied Biosystems Inc., USA). After PCR, $0.5 \mu \mathrm{l}$ of amplification product was mixed with $0.25 \mu \mathrm{l}$ GS500-LIZ Size Standard and $\mathrm{Hi}^{-\mathrm{Di}^{\mathrm{TM}}}$ Formamide (Applied Biosystems, USA) to a final volume of $10 \mu \mathrm{l}$. The resulting mixture was denatured for $5 \mathrm{~min}$ at $95^{\circ} \mathrm{C}$ and then cooled on ice for at least $3 \mathrm{~min}$. All the PCR products were genotyped on $3130 \times 1$ Genetic Analyser (Applied Biosystems Inc., Hitachi, USA), according to manufacturer's instructions.

MSI was defined as the presence of novel fragment sizes in DNA from tumor which was absent in the matched normal DNA from the same patient. Furthermore, for each informative tumor DNA/normal DNA pair, the allelic-imbalance ratio (AIR) was calculated. This is the ratio of the heights of both microsatellite alleles in the normal DNA divided by the ratio of heights in the tumor DNA from the same patient (17) (see Figure 1). An AIR value $\leq 0.67$ or $\geq 1.35$ was regarded as $\mathrm{LOH}$ (21). The LOH/MSI frequency was calculated as a percentage of $\mathrm{LOH} / \mathrm{MSI}$ alterations present in relation to all informative loci (Heterozygous DNA) for each marker. At least two independent 

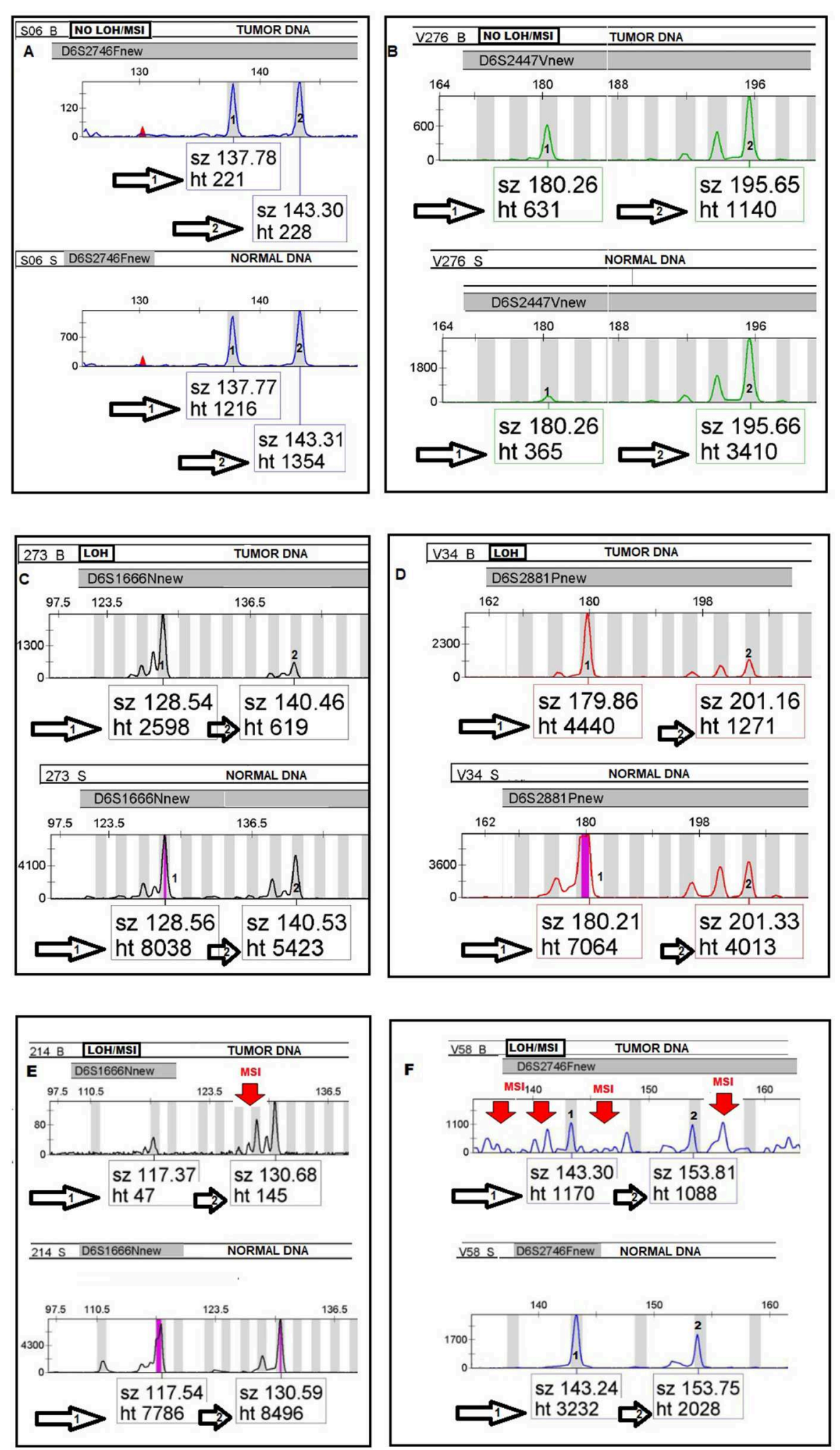

FIGURE 1 | Electropherograms (A-F) illustrating the allelic status of tumor DNA compared to normal DNA in LOH/MSI analyses by using four fluorescently-labeled microsatellites markers. Paired tumor and normal heterozygous allele ratios were analyzed by allelic-imbalance factor by calculating the quotient of the peak ratios for each informative microsatellite alleles in the normal DNA divided by the corresponding ratio found in tumor DNA from the same patient as follows; Alleles in Normal 1:Normal 2/Tumor 1:Tumor 2. 
TABLE 2 | Demographic features and the range of variables including clinical predictors measured in the subjects of the study cohort.

\begin{tabular}{|c|c|c|c|c|c|c|}
\hline Variable & BAT26 $(N=59)$ & D6S2881 $(N=81)$ & D6S2746 $(N=107)$ & D6S266 $(N=37)$ & D6S2666 $(N=97)$ & D6S2447 $(N=109)$ \\
\hline Median age, y (Range) & $40(26-77)$ & $40(26-77)$ & $42(28-77)$ & $37(24-61)$ & $39(24-66)$ & $39(24-91)$ \\
\hline Standard deviation & 9.7 & 9.7 & 9.6 & 8.4 & 8.7 & 10.6 \\
\hline Age group (years) & $n(\%)$ & $n(\%)$ & $n(\%)$ & $n(\%)$ & $n(\%)$ & $n(\%)$ \\
\hline$<30$ & $1(1.7)$ & $4(4.9)$ & $5(4.7)$ & $2(5.4)$ & $6(6.2)$ & $7(6.4)$ \\
\hline $30-40$ & $30(50.8)$ & $39(48.1)$ & $46(43)$ & $21(56.8)$ & $54(55.7)$ & $60(54.5)$ \\
\hline$>40$ & $28(47.5)$ & $38(46.9)$ & $56(52.3)$ & $14(37.8)$ & $37(38.1)$ & $42(38.2)$ \\
\hline \multicolumn{7}{|l|}{ HIV-1 status } \\
\hline HIV-1-positive & $36(61)$ & $46(56.8)$ & $56(52.3)$ & $19(51.4)$ & $62(63.9)$ & $62(56.9)$ \\
\hline HIV-1-seronegative & $23(39)$ & $35(43.2)$ & $51(47.7)$ & $18(48.6)$ & $35(36.1)$ & $47(43.1)$ \\
\hline \multicolumn{7}{|l|}{ *HPV infection } \\
\hline Single HPV infection & $19(32.2)$ & $24(29.6)$ & 36 (33.6) & $13(35.1)$ & $33(34)$ & $36(33)$ \\
\hline Multiple HPV infections & $33(55.9)$ & $39(48.1)$ & $50(46.7)$ & $18(48.6)$ & $48(49.5)$ & $54(49.5)$ \\
\hline High risk HPV & $46(78)$ & $59(72.8)$ & $81(75.7)$ & $27(73)$ & $77(79.4)$ & 86 (78.9) \\
\hline Low risk HPV & $6(10.2)$ & $4(4.9)$ & $5(4.7)$ & $4(10.8)$ & $4(4.1)$ & $4(3.7)$ \\
\hline \multicolumn{7}{|l|}{ Tumor stage } \\
\hline CIN $1 \& 2$ & $20(33.9)$ & $31(38.3)$ & $38(35.5)$ & $17(45.9)$ & $44(45.4)$ & $49(45)$ \\
\hline CIN 3 & $16(27.1)$ & $17(21)$ & $25(23.4)$ & $9(24.3)$ & $25(25.8)$ & $29(26.6)$ \\
\hline Invasive & $23(39)$ & $33(40.7)$ & $44(41.1)$ & $11(29.7)$ & $28(28.9)$ & $31(28.4)$ \\
\hline \multicolumn{7}{|l|}{ Histopathology } \\
\hline Mild dysplasia & $9(15.3)$ & $16(19.8)$ & $19(17.8)$ & $2(5.4)$ & $16(16.5)$ & $18(16.5)$ \\
\hline Moderate dysplasia & 11(18.6) & 15 (18.5) & $19(17.8)$ & $15(40.5)$ & $28(28.9)$ & $31(28.4)$ \\
\hline Carcinoma In situ & $16(27.1)$ & $17(21)$ & $25(23.4)$ & 9 (24.3) & $26(26.8)$ & 29 (26.6) \\
\hline Squamous cell carcinoma & $20(33.9)$ & $26(32.1)$ & $35(32.7)$ & 8 (21.6) & $23(23.7)$ & $24(22)$ \\
\hline Adenocarcinoma & $3(5.1)$ & 7 (8.6) & $9(8.4)$ & $3(8.1)$ & $4(4.1)$ & $7(6.4)$ \\
\hline
\end{tabular}

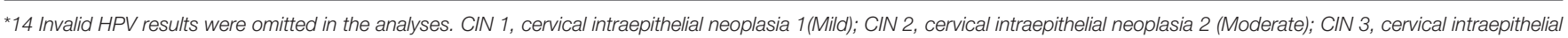
neoplasia 3 (Severe or carcinoma in situ).

experiments were required to confirm the results in each event presenting with $\mathrm{MSI} / \mathrm{LOH}$.

\section{Statistical Analysis}

Data analyses were based on previously published studies (3032). The number of cases with LOH/MSI was divided by the total number of informative cases in that region to get the fractional locus loss. If one or more markers showed LOH/MSI, the locus was regarded as demonstrating LOH/MSI. Pearson chi-squared test for homogeneity of proportions using an exact $p$-value and multivariate logistic regression model were used for statistical analyses. LOH/MSI was used as a dependent variable for testing the significance of LOH/MSI variations between different predictor variables of interest within each marker. Normal distribution two-proportion Z-score test was used to test for a statistically significant difference between two proportions within the same categorical groups. We used sensitivity, specificity and area under the receiver operating characteristic (ROC) curves to assess if age was a predictor of ICC outcome in women with LOH/MSI. The $p$-values were corrected for false discovery rate (FDR) by the Benjamini-Hochberg test and the adjusted $p$-values ( $q$-values) were reported. All odds ratios (ORs), 95\% confidence intervals (95\% CIs), the $p$-values and $q$ values calculated for multiple comparisons were 2-tailed, and considered significant if $<0.05$.

\section{RESULTS}

\section{Characteristics of the Study Cohort}

In this study paired tumor (cervical lesions) and buccal swab DNA samples were available from 164 of the original 200 recruited patients. The paired samples were collected from 24 patients with mild cervical intraepithelial neoplasia (CIN1), 42 patients with moderate cervical intraepithelial neoplasia (CIN 2), 44 patients with severe cervical intraepithelial neoplasia (CIN 3 or carcinoma in situ). and 54 patients with ICC. Seventy-four patients were HIV-1-positive and ninety patients were HIV-1seronegative. A total of 980 PCR reactions were performed, 490 each from matched tumor and buccal swab samples. The clinical and demographic features of the patients in the study cohort are summarized in Table 2. Six primer sets were used to analyse DNA microsatellites by a multiplex PCR, the number of paired samples examined for each marker is summarized in Table 3.

\section{Comparisons of LOH/MSI Frequency}

\section{(i) Between tumor DNA from precancerous lesions and ICC}

To investigate whether LOH/MSI was different between patients with precancerous lesions and ICC, the frequency of LOH/MSI in tumor DNA from precancerous lesions and ICC for each marker was compared separately. ICC tumor DNA showed more LOH/MSI only at 6p21.31 (D6S2881) than precancerous lesions 
TABLE 3 | Number of paired samples for which each microsatellite marker was successfully resolved.

\begin{tabular}{lll}
\hline & Marker & Samples \\
\hline i) & BAT26 & 59 paired samples \\
ii) & D6S2881 & 81 paired samples \\
iii) & D6S2746 & 107 paired samples \\
iv) & D6S266 & 37 paired samples \\
v) & D6S2666 & 97 paired samples \\
vi) & D6S2447 & 109 paired samples
\end{tabular}

tumor DNA, i.e., 78.8 vs. $52.1 \%$, respectively, $p=0.019$. However, the false discovery rate (FDR) q-value was not statistically significant $(q=0.114$; Table 4A).

(ii) Between tumor DNA from HIV-1-positive and HIV-1seronegative women

To investigate if LOH/MSI was different between tumor biopsies, depending on HIV-1 infection status, the frequency of LOH/MSI for all tumor biopsy DNA was compared separately in HIV1-positive and HIV-1-seronegative women. The results show that tumor DNA from HIV-1-positive women demonstrated a higher frequency of LOH/MSI than tumor DNA from HIV-1seronegative women at $6 \mathrm{p} 21.21$ (D6S2447, 74.2 vs. $42.6 \%$; $p=$ $0.001, q=0.003$ ), 6p21.31 (D6S2881, 78.3 vs. $42.9 \%$; $p=0.002$, $q=0.004), 6 \mathrm{p} 21.32(\mathrm{D} 6 \mathrm{~S} 2666,79$ vs. 57.1\%; $p=0.035, q=0.052)$, and 6p21.33 (D6S2746, 64.3 vs. 29.4\%; $p<0.001, q<0.001$ ), respectively (Table $4 \mathrm{~B}$ ).

The present study also compared the odds of having LOH/MSI (LOH/MSI-positive vs. LOH/MSI-negative cases) according to HIV-1 status for each marker. The results show that tumor biopsy DNA from HIV-1-positive women had a higher relative risk of having LOH/MSI than tumor biopsy DNA from HIV-1seronegative women for markers; D6S2881 (OR 4.8, CI 1.8-12.7, $p=0.002, q=0.004)$, D6S2746 (OR 4.3, CI 1.9-9.7, $p<0.001$, $q=<0.001)$, D6S2666 (OR 2.8, CI 1.1-7.7, $p=0.035, q=0.052$ ), and D6S2447 (OR 3.88, CI 1.6-9.5, $p=0.001, q=0.003$; Table 5).

\section{Comparison Between LOH/MSI Status and Clinical Variables}

In order to control for the effects of other variables that may influence the outcome, a multivariate logistic regression model was used to study the association of each variable by considering $\mathrm{LOH} / \mathrm{MSI}$ as a dependent variable for four markers that showed significantly different frequency among the studied groups. In this analysis, only HIV-1 status was significantly associated with LOH/MSI in DNA marker; D6S2746 $(p<0.0001, q<0.001)$, D6S2881 ( $p=0.025, q=0.15), \operatorname{D6S2447}(p=0.002, q=0.012)$, and D6S2666 ( $p=0.021, q=0.063)$ while tumor stage and histopathology were significantly associated with LOH/MSI in DNA marker D6S2666 for tumor stage $(p=0.027, q=0.054)$ and for histopathology ( $p=0.015, q=0.09$; Table 6). Furthermore, aging and cancer are highly interconnected, older age being a significant risk factor for cancer development (33). However, in cervical cancer, it has already been reported that HIV-1-positive

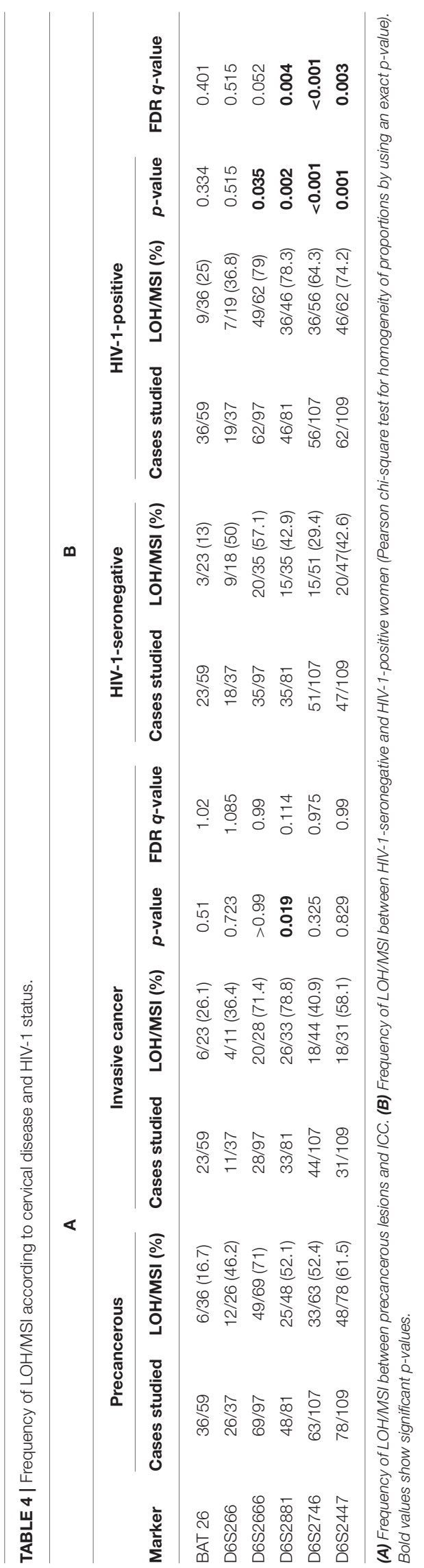


TABLE 5 | The relationship between the odds of having LOH/MSI and HIV-1 status for each marker.

Outcome

BAT $26(n=59)$

\begin{tabular}{|c|c|c|c|c|c|c|}
\hline Exposure & No LOH/MSI $(n=47)$ & LOH/MSI $(n=12)$ & OR & Cl & $p$-value & FDR $q$-value \\
\hline HIV-1-seronegative $(n=23)$ & 20 (42.6\%) & $3(25 \%)$ & Ref. & & & \\
\hline \multirow[t]{3}{*}{ HIV-1-positive $(n=36)$} & 27 (57.4\%) & $9(75 \%)$ & 2.2 & $0.5-14$ & 0.334 & 0.401 \\
\hline & \multicolumn{2}{|c|}{ D6S2881 $(n=81)$} & & & & \\
\hline & No LOH/MSI $(n=30)$ & LOH/MSI $(n=51)$ & & & & \\
\hline HIV-1-seronegative $(n=35)$ & $20(66.7 \%)$ & $15(29.4 \%)$ & Ref. & & & \\
\hline \multirow[t]{3}{*}{ HIV-1-positive $(n=46)$} & $10(33.3 \%)$ & $36(70.6 \%)$ & 4.8 & $1.8-12.7$ & 0.002 & 0.004 \\
\hline & \multicolumn{2}{|c|}{ D6S2746 $(n=107)$} & & & & \\
\hline & No LOH/MSI $(n=56)$ & LOH/MSI $(n=51)$ & & & & \\
\hline HIV-1-seronegative $(n=51)$ & $36(64.3 \%)$ & $15(29.4 \%)$ & Ref. & & & \\
\hline \multirow[t]{3}{*}{ HIV-1-positive $(n=56)$} & $20(35.7 \%)$ & $36(70.6 \%)$ & 4.3 & $1.9-9.7$ & $<0.001$ & $<0.001$ \\
\hline & \multicolumn{2}{|c|}{ D6S266 $(n=37)$} & & & & \\
\hline & No LOH/MSI $(n=21)$ & LOH/MSI $(n=16)$ & & & & \\
\hline HIV-1-seronegative $(n=18)$ & $9(42.9 \%)$ & $9(56.2 \%)$ & Ref. & & & \\
\hline \multirow[t]{3}{*}{ HIV-1-positive $(n=19)$} & $12(57.1 \%)$ & 7 (43.8\%) & 0.58 & $0.1-2.6$ & 0.515 & 0.515 \\
\hline & \multicolumn{2}{|c|}{ D6S2666 $(n=97)$} & & & & \\
\hline & No LOH/MSI $(n=28)$ & LOH/MSI $(n=69)$ & & & & \\
\hline HIV-1-seronegative $(n=35)$ & $15(53.6 \%)$ & $20(29 \%)$ & Ref. & & & \\
\hline \multirow[t]{3}{*}{ HIV-1-positive $(n=62)$} & $13(46.4 \%)$ & $49(71 \%)$ & 2.8 & $1.1-7.7$ & 0.035 & 0.052 \\
\hline & \multicolumn{2}{|c|}{ D6S2447 $(n=109)$} & & & & \\
\hline & No LOH/MSI $(n=43)$ & LOH/MSI $(n=66)$ & & & & \\
\hline HIV-1-seronegative $(n=47)$ & 27 (62.8\%) & $20(30.3 \%)$ & Ref. & & & \\
\hline HIV-1-positive $(n=62)$ & $16(37.2 \%)$ & 46 (69.7\%) & 3.88 & $1.6-9.5$ & 0.001 & 0.003 \\
\hline
\end{tabular}

Bold values show significant $p$-values.

women develop ICC earlier and at a younger age compared to HIV-1-seronegative women (34-36). Since there is limited data on the impact of age on LOH/MSI in cervical cancer development amongst HIV-1-positive women, this investigation sought to study whether age could predict ICC outcome in HIV-1-positive women with LOH/MSI in the study cohort by plotting specificity against sensitivity for each marker by using (ROC) curves to calculate the area under the curves (AUC), with $p$-values. This study found that age could predict ICC outcome in HIV-1positive women with LOH/MSI for two DNA markers, D6S2447 $(p=0.0224, q=0.044)$ and D6S2666 $(p=0.01, q=0.02$; Supplementary Figure 1).

\section{Comparison of LOH/MSI Status Between Tumor DNA From Precancerous Lesions and ICC According to HIV-1 Infection}

In order to further examine the effects of HIV-1 infection on the status of LOH/MSI, a comparison was made of LOH/MSI between tumor DNA from precancerous lesions and ICC according to HIV-1 infection for four markers; In marker D6S2746, tumor DNA from HIV-1-positive women showed significantly more LOH/MSI than tumor DNA from HIV-1seronegative women with precancer $(p=0.011, q=0.011)$. For marker D6S2447, tumor DNA from HIV-1-positive women showed more LOH/MSI than tumor DNA from HIV-1seronegative women in invasive cancer, although the $p$-value was not applicable (N/A) due to a very low number of HIV1-seronegative women with LOH/MSI. For marker D6S2666, tumor DNA from HIV-1-positive women showed significantly more LOH/MSI than tumor DNA from HIV-1-seronegative women with precancer $(p=0.001, q=0.002)$, the $p$-value was not applicable for invasive cancer due to a very low number of HIV-1-seronegative women with LOH/MSI. Finally, for marker D6S2881, tumor DNA from HIV-1-positive women showed more LOH/MSI than tumor DNA from HIV-1-seronegative women with ICC, although the $p$-value was not applicable due to very low number of HIV-1-seronegative women with LOH/MSI $(p=0.011, q=0.022$; Figure 2).

\section{Comparison of LOH/MSI Status Between HIV-1-Positive and HIV-1-Seronegative Women With Hr-HPV Infection}

Because Hr-HPV infection is a known risk factor for cervical disease development, and HIV-1 infection increases prevalence, persistence and reduces clearance of HPV-infection (1), this study examined whether LOH/MSI between tumor (cervical lesion) biopsy DNA from HIV-1-positive women and HIV-1seronegative women differ according to $\mathrm{Hr}-\mathrm{HPV}$ infection in 
TABLE 6 | Multivariate analysis in logistic regression for each marker by using LOH/MSI as a dependent variable.

D6S2746 ( $=107) \quad p$-value FDR $q$-value $\quad$ D6S2881 $(\mathrm{N}=81) \quad p$-value FDR $q$-value $\quad$ D6S2447 $(\mathrm{N}=109) \quad p$-value FDR $q$-value D6S2666 (N = 97) $p$-value FDR $q$-value

\begin{tabular}{|c|c|c|c|c|c|c|c|c|c|c|c|c|}
\hline \multicolumn{13}{|l|}{ Variables } \\
\hline Age (in years) & n (\%) & 0.256 & 0.384 & $n(\%)$ & 0.687 & 1.031 & $n(\%)$ & 0.16 & 0.48 & $n(\%)$ & 0.7 & 0.84 \\
\hline$<30$ & $5(4.7)$ & & & $4(4.9)$ & & & $7(6.4)$ & & & $6(6.2)$ & & \\
\hline $30-40$ & $46(43)$ & & & $39(48.1)$ & & & $60(55)$ & & & $54(55.7)$ & & \\
\hline$>40$ & $56(52.3)$ & & & 38 (46.9) & & & $42(38.5)$ & & & $35(36.1)$ & & \\
\hline HIV-1 status & & $<0.0001$ & $<0.001$ & & 0.025 & 0.15 & & 0.002 & 0.012 & & 0.021 & 0.063 \\
\hline HIV-1-seronegative & $51(47.7)$ & & & $35(43.2)$ & & & $62(56.9)$ & & & 35 (36.1) & & \\
\hline HIV-1-positive & 56 (52.3) & & & $46(56.8)$ & & & $47(43.1)$ & & & 62 (63.9) & & \\
\hline HPV risk & & 0.174 & 0.522 & & 0.837 & 1.004 & & 0.997 & 0.997 & & 0.919 & 0.919 \\
\hline Low risk HPV & $5(4.7)$ & & & $4(4.9)$ & & & $4(3.7)$ & & & $4(4.1)$ & & \\
\hline High risk HPV & $81(75.7)$ & & & $59(72.8)$ & & & $86(78.9)$ & & & 77 (79.4) & & \\
\hline HPV single or multiple & & 0.215 & 0.43 & & 0.935 & 0.935 & & 0.353 & 0.706 & & 0.142 & 0.213 \\
\hline Single HPV & 36 (33.6) & & & $24(29.6)$ & & & 36 (33) & & & 33 (34) & & \\
\hline Multiple HPVs & $50(46.7)$ & & & 39 (48.1) & & & $54(49.5)$ & & & $48(49.5)$ & & \\
\hline Tumor stage & & 1.171 & 1.171 & & 0.632 & 1.264 & & 0.818 & 0.981 & & 0.027 & 0.054 \\
\hline $\mathrm{CIN} 1 \& 2$ & 38 (35.5) & & & 31 (38.3) & & & $49(45)$ & & & $44(45.4)$ & & \\
\hline $\mathrm{CIN} 3$ & 25 (23.4) & & & $17(21)$ & & & 29 (26.6) & & & $25(25.8)$ & & \\
\hline Invasive & $44(41.1)$ & & & $33(40.7)$ & & & $31(28.4)$ & & & $28(28.9)$ & & \\
\hline Histopathology & & 0.646 & 0.775 & & 0.267 & 0.801 & & 0.536 & 0.804 & & 0.015 & 0.09 \\
\hline Mild dysplasia & $19(17.8)$ & & & 16 (19.8) & & & $18(16.5)$ & & & $16(16.5)$ & & \\
\hline Moderate dysplasia & $19(17.8)$ & & & 15 (18.5) & & & $31(28.4)$ & & & $28(28.9)$ & & \\
\hline Carcinoma in situ & $25(23.4)$ & & & $17(21)$ & & & $29(26.6)$ & & & $26(26.8)$ & & \\
\hline ScC & $35(32.7)$ & & & $26(32.1)$ & & & 24 (22) & & & $23(23.7)$ & & \\
\hline$A D C$ & $9(2.8)$ & & & $7(8.6)$ & & & $7(6.4)$ & & & $4(4.1)$ & & \\
\hline
\end{tabular}

Bold values show significant $p$-values. SCC, squamous cell carcinoma; ADC, Adenocarcinoma. 

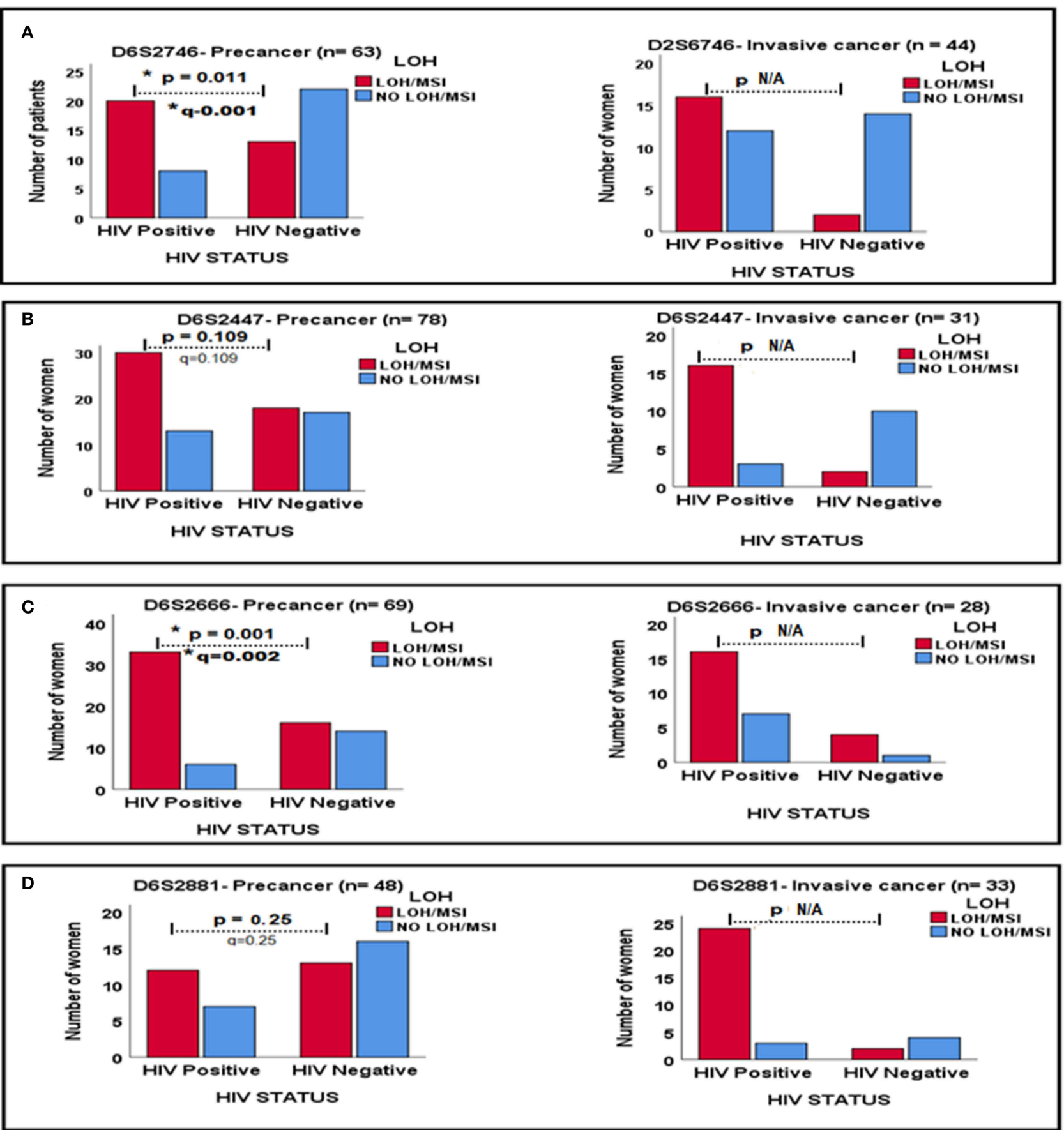

FIGURE 2 | Relationships between LOH/MSI status and HIV-1 status between precancerous lesions and ICC biopsies for four DNA markers in (A-D). * Signs mean significant $p$-value and significant $q$-value, respectively.

four markers which showed significant results. Tumor biopsy DNA from HIV-1-positive women with Hr-HPV infection showed more LOH/MSI than tumor biopsy DNA from HIV-1seronegative women with Hr-HPV infection in marker D6S2746 $(p=0.003, q=0.006$; Figure 3A), D6S2447 $(p=0.001$, $q=0.004$; Figure 3B $)$ and D6S2881 $(p=0.005, q=0.007$; Figure 3D). However, with marker D6S2666, the difference was not statistically significant $p=0.172, q=0.172$ (Figure 3C).

\section{DISCUSSION}

The present study represents the first in-depth analysis of cancerous changes, viral infection, and host LOH/MSI. The study performed comprehensive allelo-typing of isolated genomic DNA from buccal swab samples (control DNA), and from cervical precancerous lesions and ICC samples. All these samples were from HIV-1-positive and HIV-1-seronegative South African 

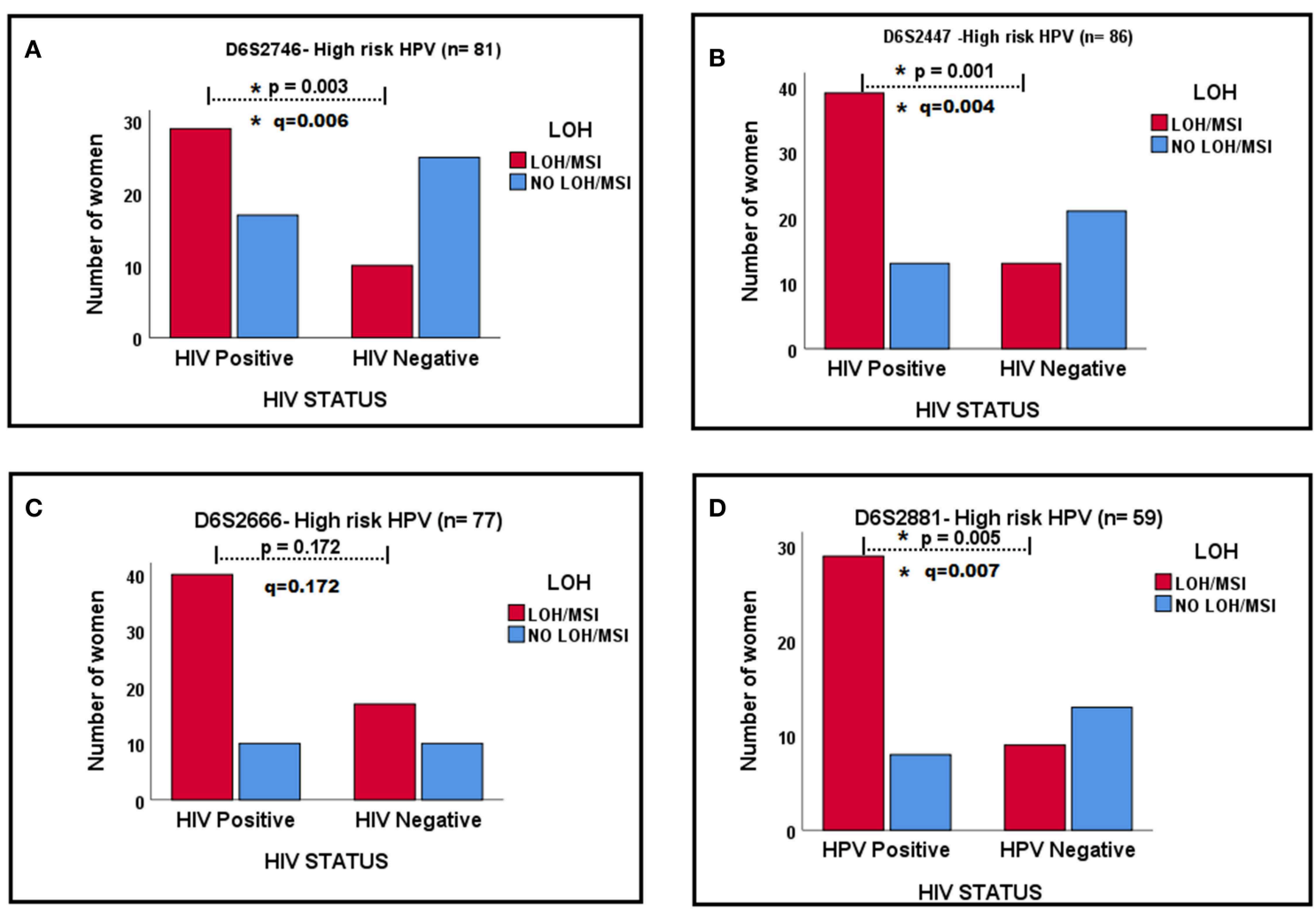

FIGURE 3 | The relationships in LOH/MSI status between HIV-1-positive and HIV-1-seronegative women with Hr-HPV infection in four markers in (A-D). * Signs mean significant $p$-value and significant $q$-value, respectively.

women, none of them were HPV vaccinated before. More importantly, this study is the first to offer an opportunity to examine the effects of HIV-1/HPV co-infection in cervical cancer by using a host molecular genetics approach. The findings revealed a significantly higher frequency of chromosomal LOH/MSI in tumor biopsy DNA from HIV-1-positive women than from HIV-1-seronegative women at the HLA II locus on chromosome 6p, as summarized in Supplementary Table 1. The investigation also contributes some important information to the existing theories of host molecular genetic alterations and cervical carcinogenesis in HIV-1-positive women that requires further investigation.

Although the duration of oncogenic HPV infection is recognized as an etiologic factor for the development of cervical disease, other host factors, and an understanding of the mechanisms involved in the cervical carcinogenesis pathway in the host, remain unknown (37). In view of the association of certain HLA II genes on chromosome 6p with cervical cancer, this study has considered the molecular genetic basis of this association in the host. The present study reports LOH/MSI from tumor DNA in precancerous lesions and cancerous lesions even from HIV-1-seronegative women. These results suggest that, in HPV infected women with cervical disease, LOH/MSI is an early genetic event in the development of cervical cancer, including the pre-invasive lesions. HIV-1 infection is an additional factor that appears to change the genetic makeup of the host cell, which in turn causes the overall genomic instability of cervical tumor DNA during the carcinogenic process. Although HPV infection alone can induce LOH/MSI at the HLA II locus in cervical tumor DNA, HIV-1 co-infection exacerbates it, potentially accelerating cervical disease progression in a subgroup of HIV1-positive women.

Since LOH/MSI play an important role in cervical carcinogenesis (21), five locus-specific DNA markers were used to study LOH/MSI at the HLA II locus on chromosome 6p. This region contains the HLA II, specifically, -DRB1 and -DQB1 which are responsible for viral infection recognition and antigen presentation to the immune system (38). Loss of an allele, or loss of a part of a chromosome at the HLA II locus, may lead to haplo-insufficiency, and can have multiple functional effects on viral immune response genes. Furthermore, if one allele of a tumor-suppressor gene is inactivated earlier at a specific locus by somatic mutations, then deletion of a second allele, as detected by $\mathrm{LOH}$, may result in loss of function of a tumor-suppressor gene or an immune-response gene (39). These results strongly support the argument that the HLA II locus on chromosome $6 \mathrm{p}$ is critical in the pathogenesis of cervical cancer. The present study has demonstrated that several genetic alterations associated with different cervical disease stages regardless of HIV-1 infection status. Findings similar to these have been reported by Harima et al. in Japan (14), by Mazurenko et al. in Russia $(40,41)$ and by Pulido et al. in the USA (30). However, the specific 
tumor-suppressor gene(s) at this locus remain unknown in different study populations.

In a previous study (13), we described an association, or likely protection from cervical cancer in HIV-1/HPV coinfected South African women, with certain HLA II genotypes. Furthermore, a study carried out by Meys et al. (42) reported that specific HLA immunogenotypes can determine the persistence of HPV infection in HIV-1 infected patients even during antiretroviral treatment. The presence of $\mathrm{HIV}-1 / \mathrm{HPV}$ coinfection in combination with specific HLA II genotypes or a haplotype may increase or decrease the risk of cervical disease development. Therefore, according to the present study, in the case of likely protective HLA II (HLA II alleles associated with decreased cancer risk), presence of LOH/MSI at the HLA II locus may further affect the protective function of these genes on HPV infection clearance (43). Additionally, genomic changes and genetic alterations in the cervical pre-cancerous lesions and ICC may be induced differently by different types of HPV, and particular HPV-specific HLA II acting in combination (44-46). Since cervical cancer is a complex genetic disease, this thesis acknowledges that the influence of epigenetics and other genomic changes on cervical cancer progression $(47,48)$, may also play a part in this process.

The presence of MSI is phenotypic evidence that DNA mismatch repair is not functioning normally (49). Therefore, structural genomic changes within the HLA II locus, may determine cervical lesions that are likely to progress to invasive cancer due to inactivation of immune-response genes and the persistence of oncogenic HPV infection. HIV-1 Tat proteins can also interact directly with functional tumor-suppressor genes in the host $(R b$ and $p 53)(10,11)$, which induces increased cell proliferation and increases the effect of Hr-HPV oncoproteins E6 and E7 in cervical carcinogenesis $(4,12)$.

Genomic instability is an early event in carcinogenesis and arises as a consequence of the disruption of critical cell-cycle check-points and failure of the DNA damage-repair system as observed in premalignant tumor DNA (Table 4 and Figure 2). These findings are similar to those of Migdalska-Sek et al. (21) who reported LOH/MSI as early events in precancerous lesions according to HPV infection status, however, the HIV1 status of their patients was unknown. Presence of LOH/MSI in premalignant tumors allows cells to acquire the additional mutations, required for malignant transformation (50). The present study further suggests that genetic instabilities are early trigger genetic events which may facilitate the subsequent establishment of all other hallmarks of cancer.

Other studies performed on LOH/MSI in head and neck cancers, colon cancer, ovarian cancer, and in cervical cancer in different populations with unknown HIV-1 status, reported frequent LOH/MSI in many chromosomes, with LOH/MSI frequencies that varied from 17 to $90 \%(9,17,18,21,30,51)$. However, in this study, the LOH/MSI frequencies vary from 13 to $79 \%$ (Table 5). The discrepancy between the present study and other published works could be due to;

(a) The quality and concentration of genomic DNA.

(b) Differences in the specific DNA markers used. (c) Intrinsic genetic differences in genomic DNA composition among different populations.

(d) The specific cancer disease of interest, whether it is MSIHigh, MSI-Low, microsatellite stable or unstable (52).

(e) The particular chromosomes examined.

(f) The specific PCR optimization conditions used (53).

The presence of dual-oncogenic HPV and HIV-1 infections has remarkable effects on genomic instability in our study population. This was demonstrated by the observation that Hr-HPV infection influenced the frequency of LOH/MSI at the HLA II locus more in cervical tumor DNA from HIV1-positive women than cervical tumor DNA from HIV-1seronegative women, except in DNA marker D6S2666 ( $p=0.172$; Figure 3C). However, when this study examined the odds of having $\mathrm{LOH} / \mathrm{MSI}$ with other predictor variables in a multivariate logistic regression analysis, LOH/MSI was significantly associated only with HIV-1 status, in all four markers (Tables 5, 6). This may be due to the effects of including many predictor variables at once, which can dilute the true association, scientific plausibility, and clinical meaningfulness of any individual result (32). However, the present study obtained interesting results by using the ROC curves (Supplementary Figure 1) that age was a significant predictor of ICC outcome in HIV-1-positive women with LOH/MSI in DNA markers D6S2447 and D6S2666. In combination with Tables 5, 6, these results suggest that, age above 30 years is a strong poor prognostic factor for ICC in HIV-1-positive women with LOH/MSI by using these two markers. Further studies are warranted on the differential effects of specific HPV genotypes and HIV-1 co-infection on the overall genomic instability of cervical tumor DNA during carcinogenesis.

The unique strengths of this study include the comparative molecular investigation of the frequency of LOH/MSI between tumors from HIV-1-positive and HIV-1-seronegative women. The examination of abnormal cervical tumor epithelial DNA and matched normal buccal mucosa epithelial DNA, as control DNA. Previously published studies have focused almost exclusively on control DNA from whole blood, which may not provide a reasonable comparison with a matched abnormal epithelial tumor DNA. Previously published studies examining tumor biopsies, have not reported on cervical tumors from HIV-1-positive women. The present analysis has focused on chromosome $6 \mathrm{p} 21$ only, with five different locus-specific DNA markers to amplify fractions of the HLA II locus. Mononucleotide repeats were disregarded due to difficult marker analyses and difficulty in distinguishing heterozygotes from homozygotes if the allele sizes were very similar, because of "stutters." The capillary electrophoresis analyses were repeated by using ethanol precipitation to clean the PCR products, wash out excess salts and unincorporated primer leftover after PCR for samples which showed poor amplification. PCR-based $\mathrm{LOH}$ assays include the ability to detect small deletions and the ability to enrich for tumor cells through microdissection (54). This investigation has been able to answer the research question by demonstrating that HIV-1/HPV co-infection does provoke additional LOH/MSI in cervical tumor DNA which may 
influence the rate of cervical disease progression in a subgroup of HIV-1-positive women.

The study limitations include the possibility of contaminated tumor samples since histologic sections of tumors usually contain a mixture of tumor cells, inflammatory cells, stromal cells, and other cellular contaminants. Limited molecular data from the study population on the presence of polymorphisms at the primer binding sites, therefore null alleles could not be excluded. Relative fluorescent units (RFUs) were very high for some swab samples and very low or absent for others which reflects unequal amplification between swab samples. In case of inadequate DNA concentration or low DNA concentration, one allele may be preferentially amplified over the other, and where one allele has insufficient amplification, termed allelic dropout. Off-scale peaks could not be sized accurately and it was not possible to determine the peak heights when the camera was saturated above 8,000 RFUs. Finally, we did not make any patient follow up in our study.

Future research opportunities may include in vivo studies to demonstrate the mechanisms of HIV-1/HPV co-infection in cervical carcinogenesis with specific HLA II alleles or haplotypes combinations, and genome-wide assays including massively parallel DNA sequencing and single-nucleotide polymorphism arrays to investigate further in-depth mechanisms and the presence of cause-effect relationships of our findings.

\section{CONCLUSIONS}

This study has demonstrated a unique relationship between LOH/MSI in cervical tumor DNA and HIV-1/HPV co-infection in a cohort of South African women. Tumor DNA from HIV1/HPV co-infected women demonstrated a higher frequency of LOH/MSI than tumor DNA from HIV-1-seronegative women at chromosome $6 \mathrm{p}$. Loss of an allele or part of a chromosome can have multiple functional effects on immune-response genes, DNA damage-repair genes and tumor-suppressor genes. The results suggest that $\mathrm{HPV}$ infection alone can induce LOH/MSI at the HLA II locus in cervical tumor DNA, whereas HIV-1 co-infection exacerbates it, possibly accelerating cervical disease progression in a subgroup of HIV-1-positive women. This work adds to the existing theories of host molecular genetic alterations and cervical carcinogenesis.

\section{DATA AVAILABILITY STATEMENT}

The raw data supporting the conclusions of this manuscript will be made available by the authors, without undue reservation, to any qualified researcher.

\section{ETHICS STATEMENT}

The studies involving human participants were reviewed and approved by all procedures performed in this study involving human participants were in accordance with the ethical standards of the institutional and/or national research committee and with the 1964 Helsinki declaration and its later amendments or comparable ethical standards. The patients/participants provided their written informed consent to participate in this study.

\section{AUTHOR CONTRIBUTIONS}

RC and RR conceived of the presented idea and developed the theory. LD and others collected the specimens. EK and GA contributed in the laboratory works of the research. Together RR, GR, A-LW, MM-S, and CG encouraged RC to investigate further, to carry out specific experiments and supervised final results and findings of this work. RC performed the computations and verified the statistical analyses methods. All other authors discussed the results and contributed equally to the final preparations of the manuscript.

\section{FUNDING}

This study was funded by The National Research Foundation of South Africa (NRF) (Grant Number: 64815), The National Health Laboratory Service of South Africa (NHLS) (Grant Number: 004_94678) and the MRC Unit for Genomic and Precision Medicine, Division of Human Genetics, Department of Pathology, Faculty of Health Sciences, University of Cape Town, South Africa.

\section{ACKNOWLEDGMENTS}

This work was based on the research supported in part by Postgraduate Academic Mobility for African Physician-Scientists (PAMAPS), organized by the Faculty of Medicine, University of Ibadan, Nigeria and funded by the European Union, and South African Medical Research Council, Clinical Gynecological Cancer Research Centre, University of Cape Town, South Africa.

\section{SUPPLEMENTARY MATERIAL}

The Supplementary Material for this article can be found online at: https://www.frontiersin.org/articles/10.3389/fonc. 2019.00951/full\#supplementary-material

Supplementary Figure 1 | Receiver operating characteristic curves by using age of patients to predict ICC between HIV-1-positive and HIV-1-seronegative women with $\mathrm{LOH} / \mathrm{MSI}$ for four significant DNA markers. (A) ROC curves for DNA marker D6S2746, showing prediction for ICC with LOH/MSI in both HIV-1-positive and HIV-1-seronegative women by using age. (B) ROC curves for DNA marker D6S2447, showing prediction for ICC with LOH/MSI in both HIV-1-positive and HIV-1-seronegative women by using age. (C) ROC curves for DNA marker D6S2666, showing prediction for ICC with LOH/MSI in both HIV-1-positive and HIV-1-seronegative women by using age. (D) ROC curves for DNA marker D6S2881, showing prediction for ICC with LOH/MSI in both HIV-1-positive and HIV-1-seronegative women by using age.

Supplementary Table 1 | Summary of the results. Where; AUC, Area under the curve. 


\section{REFERENCES}

1. Williamson AL. The interaction between human immunodeficiency virus and human papillomaviruses in heterosexuals in Africa. J Clin Med. (2015) 4:579-92. doi: 10.3390/jcm4040579

2. Menon S, Rossi R, Kariisa M, Callens S. Determining the HPV vaccine schedule for a HIV-infected population in sub Saharan Africa, a commentary. Virol J. (2018) 15:129. doi: 10.1186/s12985-018-1039-y

3. Liu G, Sharma M, Tan N, Barnabas RV. HIV-positive women have higher risk of human papilloma virus infection, precancerous lesions, and cervical cancer. Aids. (2018) 32:795-808. doi: 10.1097/QAD.0000000000001765

4. Chambuso R, Gray CM, Kaambo E, Rebello G, Ramesar R. Impact of host molecular genetic variations and HIV/HPV Co-infection on cervical cancer progression: a systematic review. Oncomedicine. (2018) 3:8293. doi: 10.7150/oncm. 25573

5. Clifford GM, Tully S, Franceschi S. Carcinogenicity of human papillomavirus (HPV) types in HIV-positive women: a meta-analysis from HPV infection to cervical cancer. Clin Infect Dis. (2017) 64:1228-35. doi: 10.1093/cid/cix135

6. McBride AA, Warburton A. The role of integration in oncogenic progression of HPV-associated cancers. PLoS Pathog. (2017) 13:e1006211. doi: 10.1371/journal.ppat.1006211

7. Gariglio P, Organista-Nava J, Alvarez-Rios E. Role of HR-HPVs E6 and E7 oncoproteins in cervical carcinogenesis. J Mol Genet Med. (2016) 10:216. doi: 10.4172/1747-0862.1000216

8. Lengauer C, Kinzler KW, Vogelstein B. Genetic instabilities in human cancers. Nature. (1998) 396:643-9. doi: 10.1038/25292

9. Cheung TH, Lo KW, Yim SF, Poon CS, Cheung AY, Chung TK, et al. Clinicopathologic significance of loss of heterozygosity on chromosome 1 in cervical cancer. Gynecol Oncol. (2005) 96:510-5. doi: 10.1016/j.ygyno.2004.10.035

10. Vernon SD, Hart CE, Reeves WC, Icenogle JP. The HIV-1 tat protein enhances E2-dependent human papillomavirus 16 transcription. Virus Res. (1993) 27:133-45. doi: 10.1016/0168-1702(93)90077-Z

11. Barillari G, Palladino C, Bacigalupo I, Leone P, Falchi M, Ensoli B. Entrance of the Tat protein of HIV-1 into human uterine cervical carcinoma cells causes upregulation of HPV-E6 expression and a decrease in p53 protein levels. Oncol Lett. (2016) 12:2389-94. doi: 10.3892/ol.2016.4921

12. Nicol AF, Pires AR, de Souza SR, Nuovo GJ, Grinsztejn B, Tristao A, et al. Cell-cycle and suppressor proteins expression in uterine cervix in HIV/HPV co-infection: comparative study by tissue micro-array (TMA). BMC Cancer. (2008) 8:289. doi: 10.1186/1471-2407-8-289

13. Chambuso R, Ramesar R, Kaambo E, Denny L, Passmore JA, Williamson AL, et al. Human Leukocyte Antigen (HLA) class II -DRB1 and -DQB1 alleles and the association with cervical cancer in HIV/HPV co-infected women in South Africa. J Cancer. (2019) 10:2145-52. doi: 10.7150/jca.25600

14. Harima Y, Harima K, Sawada S, Tanaka Y, Arita S, Ohnishi T. Loss of heterozygosity on chromosome $6 \mathrm{p} 21.2$ as a potential marker for recurrence after radiotherapy of human cervical cancer. Clin Cancer Res. (2000) 6:1079-85.

15. Hyman DM, Taylor BS, Baselga J. Implementing genome-driven oncology. Cell. (2017) 168:584-99. doi: 10.1016/j.cell.2016.12.015

16. Migdalska-Sẹk M, Czarnecka KH, Kusinski M, Pastuszak-Lewandoska D, Nawrot E, Kuzdak K, et al. Clinicopathological significance of overall frequency of allelic Loss (OFAL) in lesions derived from thyroid follicular cell. Mol Diagn Ther. (2019) 23:369-82. doi: 10.1007/s40291-019-00387-0

17. Lin JC, Wang CC, Jiang RS, Wang WY, Liu SA. Microsatellite alteration in head and neck squamous cell carcinoma patients from a betel quid-prevalent region. Sci Rep. (2016) 6:22614. doi: 10.1038/srep22614

18. Kamat N, Khidhir MA, Alashari MM, Rannug U. Microsatellite instability and loss of heterozygosity detected in middle-aged patients with sporadic colon cancer: a retrospective study. Oncol Lett. (2013) 6:1413-20. doi: 10.3892/ol.2013.1573

19. Vassileva V, Millar A, Briollais L, Chapman W, Bapat B. Genes involved in DNA repair are mutational targets in endometrial cancers with microsatellite instability. Cancer Res. (2002) 62:4095-9.

20. Migdalska-Sęk M, Pastuszak-Lewandoska D, Brzezianska E. MSI and LOH in the development and prognosis of follicular cell-derived thyroid tumours. Endokrynol Polska. (2012) 63:126-36.
21. Migdalska-Sęk M, Karowicz-Bilinska A, Pastuszak-Lewandoska D, Czarnecka $\mathrm{KH}$, Nawrot E, Domanska-Senderowska D, et al. Assessment of the frequency of genetic alterations (LOH/MSI) in patients with intraepithelial cervical lesions with HPV infection: a pilot study. Med Oncol. (2016) 33:51. doi: 10.1007/s12032-016-0763-7

22. OpenStaxCollage. Cancer and the cell cycle. In: RiceUniversity, editor. Biology. Cell Reproduction. Houston, TX: OpenStax Collage (2013). p. 291-2.

23. Department of Health RoSA. National HIV counselling and testing policy guidelines. In: Health Do, editor. Department of Health (2015). p. 8-12. Available online at: www.health-e.org.za

24. López-González A, Ibeas Millán P, Provencio M. DNA damage and repair in cancer therapy. J Cancer Sci Ther. (2013). S8. doi: 10.4172/1948-5956.S8-002

25. Isaiah IN, Joseph MB. Comparative dynamics of DNA isolated from buccal Swab for Forensic Investigation "Pro and Post Brushing from Some Adult Males in Benin Metropolis, Nigeria”. J Forensic Sci Criminol. (2016) 4:501. doi: 10.15744/2348-9804.4.501

26. Qiagen Q. South Africa Protocol: Isolation of Total DNA From Surface and Buccal Swabs. (2012). p. 13-6. Available online at: https://www.qiagen.com

27. Brys M, Migdalska-Sęk M, Pastuszak-Lewandoska D, Forma E, Czarnecka K, Domanska D, et al. Diagnostic value of DNA alteration: loss of heterozygosity or allelic imbalance-promising for molecular staging of prostate cancers. Med Oncol. (2013) 30:391. doi: 10.1007/s12032-012-0391-9

28. Ramos TDP, Amorim LMF. Molecular biology techniques for loss of heterozygosity detection: the glioma example. J Brasil Patol Med Lab. (2015) 51:189-96. doi: 10.5935/1676-2444.20150033

29. Gan C, Love C, Beshay V, Macrae F, Fox S, Waring P, et al. Applicability of next generation sequencing technology in microsatellite instability testing. Genes. (2015) 6:46-59. doi: 10.3390/genes6010046

30. Arias-Pulido $\mathrm{H}$, Joste $\mathrm{N}$, Wheeler CM. Loss of heterozygosity on chromosome 6 in HPV-16 positive cervical carcinomas carrying the DRB1*1501-DQB1*0602 haplotype. Genes Chromosomes Cancer. (2004) 40:277-84. doi: $10.1002 /$ gcc. 20048

31. Hu ZD, Zhou ZR, Qian S. How to analyze tumor stage data in clinical research. J Thor Dis. (2015) 7:566-75. doi: 10.3978/j.issn.2072-1439.2015.04.09

32. Ranganathan P, Pramesh CS, Aggarwal R. Common pitfalls in statistical analysis: logistic regression. Perspect Clin Res. (2017) 8:148-51. doi: 10.4103/picr.PICR_123_17

33. Cho WC. Molecular connections of aging and cancer. Aging Dis. (2017) 8:685-7. doi: 10.14336/AD.2017.0822

34. Chambuso RS, Kaambo E, Stephan S. Observed age difference and clinical characteristics of invasive cervical cancer patients in tanzania; a comparison between HIV-positive and HIV-negative women. J Neoplasm. (2017) 2:16. doi: 10.21767/2576-3903.100025

35. Chambuso RS, Shadrack S, Lidenge SJ, Mwakibete N, Medeiros RM. Influence of HIV/AIDS on cervical cancer: a retrospective study from Tanzania. J Glob Oncol. (2017) 3:72-8. doi: 10.1200/JGO.2015.002964

36. Abraham AG, D’Souza G, Jing Y, Gange SJ, Sterling TR, Silverberg MJ, et al. Invasive cervical cancer risk among HIV-infected women: a North American multicohort collaboration prospective study. I Acqui Immune Defic Syndr. (2013) 62:405-13. doi: 10.1097/QAI.0b013e31828177d7

37. Bahrami A, Hasanzadeh M, Shahidsales S, Farazestanian M, Hassanian SM, Moetamani Ahmadi M, et al. Genetic susceptibility in cervical cancer: from bench to bedside. J Cell Physiol. (2018) 233:1929-39. doi: 10.1002/jcp.26019

38. Chen D, Juko-Pecirep I, Hammer J, Ivansson E, Enroth S, Gustavsson I, et al. Genome-wide association study of susceptibility loci for cervical cancer. J Natl Cancer Institute. (2013) 105:624-33. doi: 10.1093/jnci/ djt051

39. Roberts LR, LaRusso NF. Potential roles of tumor suppressor genes and microsatellite instability in hepatocellular carcinogenesis in southern African blacks. World J Gastroenterol. (2000) 6:37-41. doi: 10.3748/wjg.v6.i1.37

40. Mazurenko N, Attaleb M, Gritsko T, Semjonova L, Pavlova L, Sakharova O, et al. High resolution mapping of chromosome 6 deletions in cervical cancer. Oncol Rep. (1999) 6:859-63. doi: 10.3892/or.6.4.859

41. Mazurenko NN, Bliev A, Bidzhieva BA, Peskov D, Snigur NV, Savinova EB, et al. [Loss of heterozygosity at chromosome 6 as a marker of early genetic alterations in cervical intraepithelial neoplasias and microinvasive carcinomas]. Molekuliarnaia Biol. (2006) 40:436-47. doi: 10.1134/S0026893306030058 
42. Meys R, Purdie KJ, de Koning MN, Quint KD, Little AM, Baker F, et al. HLA immunogenotype determines persistent human papillomavirus virus infection in HIV-infected patients receiving antiretroviral treatment. J Infect Dis. (2016) 213:1717-24. doi: 10.1093/infdis/jiw038

43. Magnusson PK, Gyllensten UB. Cervical cancer risk: is there a genetic component? Molecul Med Today. (2000) 6:1458. doi: 10.1016/S1357-4310(00)01685-3

44. Grozdanov P, Hadjidekova S, Dimova I, Nikolova I, Toncheva D, Ganchev $\mathrm{G}$, et al. Characterization of genomic changes in the cervical pre-cancerous lesions and tumors induced by different types of human papillomaviruses. Virusdisease. (2016) 27:271-6. doi: 10.1007/s13337-016-0338-4

45. Alaez-Verson C, Berumen-Campos J, Munguia-Saldana A, Flores-Aguilar H, Guardado-Estrada M, Rodriguez-Gomez A, et al. HPV-16 and HLA-DRB1 alleles are associated with cervical carcinoma in Mexican Mestizo women. Arch Med Res. (2011) 42:421-5. doi: 10.1016/j.arcmed.2011.07.002

46. Beskow AH, Moberg M, Gyllensten UB. HLA class II allele control of HPV load in carcinoma in situ of the cervix uteri. Int J Cancer. (2005) 117:5104. doi: 10.1002/ijc. 21204

47. Duenas-Gonzalez A, Lizano M, Candelaria M, Cetina L, Arce C, Cervera E. Epigenetics of cervical cancer. An overview and therapeutic perspectives. $\mathrm{Mol}$ Cancer. (2005) 4:38. doi: 10.1186/1476-4598-4-38

48. Ojesina AI, Lichtenstein L, Freeman SS, Pedamallu CS, Imaz-Rosshandler I, Pugh TJ, et al. Landscape of genomic alterations in cervical carcinomas. Nature. (2014) 506:371-5. doi: 10.1038/nature12881

49. Larrea AA, Lujan SA, Kunkel TA. SnapShot: DNA mismatch repair. Cell. (2010) 141:730.e1. doi: 10.1016/j.cell.2010.05.002

50. Chen JJ. Genomic instability induced by human papillomavirus oncogenes. $N$ Am J Med Sci. (2010) 3:43-7. doi: 10.7156/v3i2p043

51. Alves LN, Wolfgramm EV, de Castro Neto AK, Louro ID. Analysis of microsatellite instability and loss of heterozygosity in ovarian cancer: a study in the population of Espirito Santo, Brazil. Genet Molecul Res. (2013) 12:19962001. doi: 10.4238/2013.June.14.2

52. Popat S, Hubner R, Houlston RS. Systematic review of microsatellite instability and colorectal cancer prognosis. J Clin Oncol. (2005) 23:60918. doi: 10.1200/JCO.2005.01.086

53. Matevska-Geshkovska N, Staninova-Stojovska M, KapedanovskaNestorovska A, Petrushevska-Angelovska N, Panovski M, Grozdanovska $\mathrm{B}$, et al. Influence of MSI and 18q LOH markers on capecitabine adjuvant monotherapy in colon cancer patients. Pharmacogenom Personalized Med. (2018) 11:193-203. doi: 10.2147/PGPM.S172467

54. Hunt JL. Loss of Heterozygosity. In: Tubbs RR, Stoler MH, editors. Cell and Tissue Based Molecular Pathology. Philadelphia, PA: Churchill Livingstone (2009). p. 50-5. doi: 10.1016/B978-044306901-7.50010-9

Conflict of Interest: Opinions, findings and conclusions, or recommendations expressed in this publication generated by the listed organizations supported research is that of the authors alone, and that the organizations accept no liability whatsoever in this regard.

The authors declare that the research was conducted in the absence of any commercial or financial relationships that could be construed as a potential conflict of interest.

Copyright (c) 2019 Chambuso, Kaambo, Denny, Gray, Williamson, Migdalska-Sek, Agenbag, Rebello and Ramesar. This is an open-access article distributed under the terms of the Creative Commons Attribution License (CC BY). The use, distribution or reproduction in other forums is permitted, provided the original author(s) and the copyright owner(s) are credited and that the original publication in this journal is cited, in accordance with accepted academic practice. No use, distribution or reproduction is permitted which does not comply with these terms. 